Fecha de recepción: marzo 2008 Fecha de aceptación: mayo 2008 Versión final: noviembre 2008

\section{La fotografía como soporte de la memoria}

\author{
Florencia Bustingorry ${ }^{(*)}$ y Valeria Mugica ${ }^{(*)}$
}

\footnotetext{
${ }^{(*)}$ Magíster en Ciencia Política y Sociología (FLACSO). Licenciada en Comunicación Social (Unicén). Profesora en Comunicación Social (Unicén).

${ }^{(*)}$ Licenciada en Sociología (UBA). Maestranda en Historia del Arte Latinoamericano en UNSAM. Se desempeña como docente e investigadora en la Facultad de Ciencias Sociales (UBA).
}

Resumen: En este trabajo se plantea como objetivo abordar el uso de la fotografía como soporte de la memoria en la demanda pública por los derechos humanos. En este caso particular sobre la representación de las víctimas del sistema represivo y como mecanismo de reclamo por la justicia ante la represión ilegal llevada adelante por el terrorismo de Estado durante la última dictadura militar en Argentina. Más específicamente, el uso de la foto-carnet en el reclamo público por el destino de los desaparecidos en la Argentina.

Se hará hincapié en el uso que las distintas organizaciones de Derechos Humanos hacen de las fotoscarnets como modo de representación de los desaparecidos durante los actos de conmemoración del 24 de marzo en la Plaza de Mayo. Se sostiene que el uso de las fotos-carnets actualiza la demanda por la restitución del desaparecido. Estas prácticas atraviesan tanto el espacio público como el privado, surgiendo desde lo privado hacia lo público. La exigencia que actualiza la foto-carnet explicita la restitución de este sujeto en su condición de ciudadano dentro de la ley, por fuera de la clandestinidad. E intenta re-instalar la imagen de estos sujetos en el espacio público.

Palabras claves: ausencia - conmemoración - fotografía - identidad - ley - memoria - sujeto.

[Resúmenes en inglés y portugués en la página 101]

La fotografía ha sido objeto de múltiples usos y abordajes. Se ha empleado con diferentes fines y a través de diversas técnicas: la foto de familia, el registro documental, la foto periodística, el retrato, los paisajes, la foto turística, el registro burocrático, entre otros. Lo cierto es que en todas estas ocasiones el uso de la fotografía pareciera estar asociado al carácter de autenticidad en la representación sobre el referente al que apunta. En términos de Roland Barthes (2006) la foto jamás se distingue de su referente, o por lo menos no lo hace en el mismo acto o para todo el mundo. Desde esta perspectiva la fotografía tiene algo de tautológica: "Diríase que la Fotografía lleva siempre su referente consigo, estando marcados ambos por la misma inmovilidad amorosa o fúnebre, en el seno mismo del mundo en movimiento: están pegados el uno al otro, miembro a miembro, como el condenado encadenado a un cadáver en ciertos suplicios" (p. 31).

En algunas ocasiones, se recurre a la fotografía como medio de prueba de la existencia de un sujeto 
o como demostración de un acto, considerando que la misma constituye un documento que es en sí mismo una prueba irrefutable.

En distintas instancias judiciales, la fotografía es utilizada como prueba de la autenticidad de un suceso. La existencia de los sujetos ante el Estado es registrada a través de las múltiples "huellas" que éstos pueden dejar, el rostro es una de ellas y adquiere una gran relevancia en los procedimientos de: procesamiento de información, clasificación, fichaje, catalogación, descripción, identificación e individuación. En este sentido, la estandarización y uso de la foto-carnet asociada a las funciones estatales, es resultado de dos procesos relacionados: el desarrollo y la modernización del Estado en el registro y catalogación de sus ciudadanos. Proceso éste que coincide con el avance de nuevas técnicas, que estandarizan los procesos fotográficos, permitiendo destacar el rostro humano con todos sus detalles, en contraste blanco/negro. Si el rostro es preponderantemente la vitrina de la persona (Elias, 1994), la foto-carnet resalta el carácter de unicidad e indivisibilidad ante los demás y ante las instituciones que requieren la prueba de autenticidad de la identidad.

Por otro lado, pareciera ser que aquello que no llega a ser registrado por la cámara no tiene una entidad propia, se duda de su existencia o se ha esfumado en el olvido, esto es: no ha quedado registrado por el ojo de la cámara. La función de la fotografía en las historias de vida es fundamental, a través de las imágenes se realiza una rememoración de los sucesos pasados y sus protagonistas. En relación con la pérdida de fotos personales Laura Bonaparte considera que:

Puedo reconstruir hechos, conductas, mi militancia política, pero, ¿cómo reconstruir la imagen si esta reconstrucción es pura subjetividad? No tengo memoria para mi rostro feliz, en la pileta, nadando con mis hijos .... En fin no encuentro rastros de esa imagen feliz con todos mis hijos y cuando ellas y ellos iban pariendo. Tampoco puedo encontrarme en la que me devuelve el espejo. Así es. No hay continuidad en la corroboración del recuerdo (2006, p. 20).

La foto es siempre una imagen de lo que nunca va a volver a suceder, de un tiempo que ya fue, como dice Roland Barthes: "Lo que la fotografía reproduce al infinito únicamente ha tenido lugar una sola vez: la fotografía repite mecánicamente lo que nunca más podrá repetirse existencialmente.” (2006, p. 28-29).

Es que la fotografía representa una interrupción del tiempo, por lo tanto de la vida. El segmento elegido de lo real a partir del momento en que fue registrado permanecerá interrumpido y aislado en la bidimensión de la superficie sensible (Kossoy, 2001, p. 36). Esta imagen se constituirá ahora en otra realidad, la del documento, que desde la perspectiva de Kossoy, adquiere una entidad autónoma y da inicio a otro proceso: el de "la vida del documento" que no sólo conserva la imagen del pasado sino que ahora forma parte del mundo.

Como prueba de que existieron otros tiempos y otros sujetos es que la fotografía remite a lo que ya no es, pero que al parecer sí existió realmente. Este es uno de los sentidos en lo que la foto es utilizada para el reclamo por el destino de quienes fueron objeto de la desaparición forzada durante la última dictadura militar en Argentina. ${ }^{1}$ En principio la foto estaría diciendo: "esta persona existió", "tiene una cara", "un nombre", "es única”; y por otro el recurso a la foto-carnet estaría rescatando su carácter de ciudadano, de sujeto ante la ley, intentando reponer un lugar simbólico desde el cual fue desplazado. La utilización de la foto-carnet en este tipo de reclamo público le da un carácter distintivo al sentido otorgado tanto a la foto como "soporte de la memoria" como a los sujetos que se 
representan a partir de esas imágenes.

En relación con el tópico antes mencionado es dable destacar que la construcción de las memorias sociales se produce a través de distintas prácticas y discursos. El repudio a la última dictadura militar en la Argentina y el reclamo de justicia siempre presentes en el espacio público, han dado lugar a la producción de diversas formas de movilización y de manifestaciones simbólicas que han utilizado para estos fines diferentes soportes sumamente amplios y originales.

En este trabajo nos planteamos como objetivo abordar el uso de las fotografías como forma de representación de las víctimas del sistema represivo y como mecanismo de reclamo por la justicia ante la represión ilegal llevada adelante por el terrorismo de Estado durante la última dictadura militar. Más específicamente, el uso de la foto-carnet en el reclamo público por el destino de los desaparecidos en la Argentina.

Específicamente haremos hincapié en el uso que las distintas organizaciones de Derechos Humanos hacen de las fotos-carnets como modo de representación de los desaparecidos durante los actos de conmemoración del 24 de marzo en la Plaza de Mayo.

Consideramos que los contextos de los aniversarios del golpe de Estado ocurrido el 24 de marzo de 1976 se convierten en instancias donde los protagonistas de este proceso adquieren visibilidad en el espacio público. En las manifestaciones callejeras, los desaparecidos por acción del aparato represivo aparecen en el ámbito público a través de todo un universo de discursos y prácticas que hacen presente su ausencia. Esta presencia se representa a través de un gran abanico iconográfico, que funciona como soporte de la memoria, que va desde la utilización de guardapolvos blancos vacíos, siluetas (con o sin nombre), fotografías en pancartas hasta las sábanas negras con fotografías. Ludmila da Silva Catela (1997) define a los soportes de la memoria como aquellos recursos, sean escritos o visuales, que mantienen una continuidad en el tiempo mas allá de los acontecimientos puntuales o momentos de crisis. La autora dice que en el caso de los desaparecidos:

Nominando, corporizando en una foto, los cuadros refuerzan la idea de un sufrimiento con rostro, lazos familiares, historia, nombre y apellido. Esta restitución permite que una imagen de persona perdida dentro de la categoría 'desaparecido', salga del anonimato y recobre su identidad, a comenzar por uno de los rasgos de distinción más importantes, el rostro, que como dice Elias, más que cualquier otra parte del cuerpo es la vitrina de la persona. (p. 113).

Sostenemos que el uso de las fotos-carnets actualiza la demanda por la restitución del desaparecido. Estas prácticas atraviesan tanto el espacio público como el privado, surgiendo desde lo privado hacia lo público. La exigencia que actualiza la foto-carnet explicita la restitución de este sujeto en su condición de ciudadano dentro de la ley, por fuera de la clandestinidad.

Paradójicamente la foto-carnet que funciona como el dispositivo de identificación, control, fichaje y clasificación de los sujetos por parte del sistema burocrático de los Estados, es reapropiada por la sociedad civil en la instancia de reclamo de los organismos de derechos humanos argentinos para reclamar la reinserción de los desaparecidos en el estado de derecho.

La exhibición de la foto-carnet en las manifestaciones callejeras pone en evidencia los rostros de aquellos que fueron apropiados por un sistema de represión ilegal, que sustrajo los cuerpos a la mirada del "otro", y que básicamente utilizó el dispositivo de la foto (primordialmente del rostro) para identificar a sus víctimas, borrando toda huella de su paradero posterior a la entrada en el sistema 
represivo. También, en esta instancia la foto-carnet de las pancartas o sábanas de las organizaciones por los derechos humanos hace presente en la escena pública, el doble reclamo por la restitución del cuerpo del desaparecido (de esa traza perdida) y la restitución de la identidad del ciudadano, protagonista de un proceso histórico que aun no se ha cerrado.

Hay así un "juego de inversiones". El sistema utilizaba la "marca" del rostro para identificar a quienes iban a ser objeto de su poder arbitrario y despojaba a estos mismos sujetos de esta categoría a través de un dispositivo de "borramiento" de la mirada externa, de su carácter de sujeto/ciudadano. La fotocarnet es una marca indeleble en toda documentación pública, desde un documento de identidad, pasando por un carnet filiatorio, hasta un pasaporte, en el mundo burocrático somos un rostro en la "papeleta", el mismo debe coincidir con la cara de quien lo porta, sirve para el fichado y como prueba de la existencia de los sujetos en el sistema.

Es así que este dispositivo de control, que funciona en el mundo burocratizado, imprime sobre el papel lo que ya no está, la huella de lo que se ha sido y no se volverá a ser jamás. Las fotos de los desaparecidos los muestran como jóvenes de veinte años, el tiempo no pasa para estos sujetos cuyo rostro queda impreso en la juventud. Eternos jóvenes, convertidos socialmente en padres después de más de veinte años de su muerte, dan a luz a unos HIJOS que tienen su misma edad (Castellani, 2003, p. 25).

Como bien dice Reati, haciendo alusión a los recordatorios de los desaparecidos, por un resultado tal vez no buscado al escoger un retrato de documento público para el recordatorio, se subvierte el poder regulador del Estado que llevó a cabo los crímenes. La memoria es inseparable del archivo fotográfico y éste está regulado por la doble lógica del álbum familiar y el prontuario policial (Giunta). Se verifica así la paradoja de que aquella foto de documento que originalmente servía para un propósito clasificatorio y regulador ahora cumple un papel de denuncia (Reati, 2007, p. 168).

\section{El 24 de marzo en la Plaza de Mayo}

Seleccionamos para nuestro análisis los recordatorios del 24 de marzo ya que esta fecha se constituye en paradigmática en el reclamo de justicia y en la actualización de la memoria de las víctimas de la última dictadura militar. En este contexto, los organismos de derechos humanos y los movimientos sociales son protagonistas de la escena pública.

Cabe señalar que los actos de conmemoración se establecen como espacios de una dinámica social y relacional que permite recordar juntos, donde la construcción del pasado no es un cúmulo de experiencias y recuerdos meramente individuales. Es a través de esta mise en escena de la memoria donde la construcción de lo que se recuerda o conmemora trasciende el ámbito de lo individual y se convierte en la base de futuras reminiscencias (Middleton y Edwards, 1992, p. 23). En este proceso de rememorar experiencias compartidas los sujetos reinterpretan su pasado, que se convierte en el contenido de lo que se recordará en el futuro.

Los actos de conmemoración elaboran una recordación intencional de procesos sociales o sujetos a los que se adscribe un significado histórico: "La gente recuerda y celebra hechos y personas que forman parte de una identidad y concepción cultural y generacional común reconocida por todos”. (p. 24).

Los sentidos sobre el pasado se elaboran sobre diversas versiones de la historia. Los relatos se construyen desde la organización retórica del recuerdo y el olvido, que se evidencia (en principio) en las versiones contradictorias del pasado y sobre a quién culpar, excusar, reconocer, honrar o confiar (p. 25). Las manifestaciones que conmemoran el aniversario del golpe del 24 de marzo y a la figura de 
los desaparecidos producen una visión propia de la historia y renuevan el sentido sobre este proceso. Las memorias sociales se construyen y establecen a través de prácticas y de "marcas". En términos de Jelin son prácticas sociales que se instalan como rituales; marcas materiales en lugares públicos e inscripciones simbólicas, incluyendo los calendarios (2002, p. 2). Estas prácticas de construcción de las memorias se producen en contextos determinados y es en este sentido que adquieren una dimensión histórica.

La conmemoración de determinados acontecimientos o el establecimiento de un calendario de fechas socialmente significativas se establecen social e históricamente. En este proceso de confrontación por la versión legítima del pasado "la lucha por la posesión e interpretación de la memoria está enraizada en el conflicto y la interacción de intereses y valores sociales, políticos y culturales en el presente" (1992, p. 19).

Estos actos conmemorativos se sitúan en diversos lugares, en este caso nos interesan aquellos que ocurren en la Plaza de Mayo, ya que ésta es paradigmática en la vida política argentina. La Plaza se constituye en un lugar de visibilidad pública cuya finalidad es ser visto y oído. Al respecto Silvia Sigal considera que no es posible dar cuenta de los potenciales destinatarios de esta mirada, no obstante están presentes:

Los 'otros' -amigos y enemigos- y los participantes mismos -que se muestran su potencia y engendran (siquiera efímeramente) su calidad de entidad colectiva-: la presencia pública no es tan sólo la expresión de entidades previamente constituidas sino que contribuye a producirlas, modelarlas o consolidarlas. Las demostraciones tienen in fine un tercer destinatario, un ojo público, que es simultáneamente la garantía de su existencia. (2006, p. 17).

Respecto del reclamo por los derechos humanos, Sigal (1999) afirma que la movilización de las Madres de Plaza de Mayo vuelve a convertir a la Plaza en el sitio donde las demandas se dirigen al poder.

Símbolo mayor de la historia argentina, las Madres inventaron una nueva Plaza y quedaron bautizadas por ella. Fueron punto de origen de una nueva tradición que perdura inscripta alrededor de la Pirámide; los pañuelos blancos en el suelo y el pequeño obelisco con las únicas marcas materiales de acontecimientos que tuvieron a la plaza por escena... Desde hace 20 años, cada jueves, a la misma hora, reiteran lo que es ya una ceremonia fuertemente ritualizada, caminando ahora sobre su propio monumento (p. 360-361).

Es evidente que las movilizaciones en este espacio público de la Plaza de Mayo instalan al desaparecido en las calles. A través de la ritualidad que se imprime en estos actos se invierte el principio de la desaparición, de la pérdida del rastro del sujeto. A partir del uso de las siluetas y las foto-carnet el desaparecido se constituye en un sujeto desdoblado, que forma parte de un colectivo (por el modo en que se le perdió el rastro) pero que a su vez tiene un nombre y un apellido: las siluetas muestran de lejos la repetición de lo mismo, a partir de una identidad que los abarca (la de desaparecidos) pero las fotos de cerca muestran la diferencia de cada uno de ellos, con un nombre, una cara, una historia (González Bombal, 1987, p. 156). 


\section{Fotografía e identidad}

$\mathrm{Al}$ abordar el proceso de construcción de la identidad de los desaparecidos a través de la fotografía, es pertinente dar cuenta de la conceptualización de Emilio De Ipola (1997). El autor define las identidades colectivas como presididas por la amenaza y la creencia como piezas esenciales. En sus propios términos: “...Un dispositivo institucional, un gesto, una acción, tanto como un discurso (no necesariamente "performativo") pueden funcionar como amenaza, esto es, como un peligro que se cierne sobre un individuo o un grupo, peligro imputable a otro individuo o grupo." (p. 67)

Quienes pugnan por el esclarecimiento de los crímenes cometidos durante la última dictadura se enfrentan a la amenaza del olvido; sus prácticas y sus consignas evidencian esta lucha por el mantenimiento del recuerdo vivo de quienes fueron víctimas. El olvido constituiría la legitimación de la injusticia y el cierre de un debate que está inconcluso.

Para mantener la memoria, se apela a diversas formas de representar al ausente en el espacio público: desde los relatos de sus vidas a través de muestras de fotografías, objetos personales, historias de vida, manifestaciones públicas, hasta la presencia de los organismos de derechos humanos en el espacio público. Los mecanismos a través de los que se busca preservar la memoria han cambiado, pero la movilización en el espacio público se constituye en la marca diferencial del movimiento por los derechos humanos, no por el carácter de público sino por la modalidad misma que ella adquiere. Respecto de la amenaza en la constitución de la identidad, Ernesto Laclau pone el acento en la negatividad y la reacción, como constitutivas per se,

En el mismo movimiento por el cual la amenaza se dirige a alguien y cuestiona su existencia o su integridad, y por lo tanto el destinatario de la amenaza reacciona a ella y la enfrenta, se instaura un antagonismo en los marcos del cual el amenazado 'Juega' -en varios sentidos- su identidad: la descubre, la asume, lucha por reafirmarla y consolidarla; o al contrario la redefine o la pierde. Bajo la figura de la amenaza la negatividad opera a la vez como condición de imposibilidad y de posibilidad de una identidad. (1997, p. 71).

La creencia es el cimiento y garante de la identidad, en tanto la amenaza opera como motor de la reacción de los sujetos.

La creencia que sustenta la identidad de quienes luchan por los derechos humanos es la justicia, el poder llegar a instancias donde los culpables sean juzgados. Esta constituye la esperanza que mueve sus acciones, el motor de las prácticas concretas. Si sus acciones no estuvieran impulsadas por la creencia en la justicia no habría movilización o reclamo posible.

La identidad de los desaparecidos es construida desde los "otros", que a través de sus prácticas y discursos les otorgan sentidos diferenciales. Entre las múltiples manifestaciones simbólicas que funcionan como soportes de la memoria la fotografía ha ido ganando su propio espacio en la narrativa sobre los protagonistas de la última dictadura militar.

El uso de la fotografía en las movilizaciones por el reclamo de los derechos humanos fue de la mano del proceso de transformación de identidades de todos los sujetos involucrados en el tema, de los reclamos por la justicia y de los contextos políticos y sociales. Los soportes de la memoria, que se utilizaron para la demanda de justicia y verdad en las movilizaciones públicas han cambiado. Durante la época de la dictadura se apeló al uso de la nominación de las víctimas, a través de grandes carteles donde se colocaba el nombre, la fecha de desaparición y un signo de pregunta. En algunos casos se 
incluían otros datos como profesión y edad (da Silva Catela, 2001, p. 133). También se recurría a la representación del ausente a través de siluetas vacías o manos. A partir de 1983, en que se produce el retorno a la democracia, se registra la coexistencia en el uso de diversos soportes de la memoria; a la exhibición de las siluetas y los carteles identificatorios se le incorpora el uso de la fotografía. Las fotos que se utilizan van desde la foto carnet, hasta la fotografía familiar, este recurso ha sido muy útil para las Abuelas de Plaza de Mayo en la búsqueda de los nietos desaparecidos, ya que a través de la divulgación de imágenes de los niños con sus padres se han podido establecer relaciones de parentesco.

Algunos de los elementos que son propios de las manifestaciones de los organismos de derechos humanos argentinos, como por ejemplo el pañuelo blanco en el caso de las Madres de Plaza de Mayo, el uso de fotografías de desaparecidos en el espacio público y de prácticas como los escraches se pueden situar en un límite difuso, poco claro, entre documentación, protesta y performance ${ }^{2}$ (Schindel, 2008, p. 411). Hay en este tipo de prácticas una lógica dinámica en la producción constante del soporte de la memoria, a diferencia de los monumentos donde la piedra o la imagen estática es lo primordial, la performace implica una construcción siempre viva de la memoria, el carácter performativo de estas prácticas hacen al dinamismo propio del reclamo por los derechos humanos.

En los actos de conmemoración del golpe del 24 de marzo se utilizan múltiples fotografías del rostro de los desaparecidos que son portadas por sus familiares en la calle. Estas fotografías muestran a jóvenes casi congelados en el tiempo, con peinados y aspectos de adolescentes de otra época, en esta escena se produce un encuentro entre esos rostros inmóviles y la movilización pública que reclama una respuesta a la problemática de los derechos humanos.

En este contexto la foto contribuye a crear un impacto en la visibilidad de las víctimas: en el pasaje del uso de las siluetas blancas a las fotos hay un desplazamiento que va de un espacio vacío, un contorno en blanco a una cara que mira a quien se acerca, que interpela con la fuerza de su mirada y tiende a producir el efecto de identificación. Las fotos resultan ser testimonio de la entidad y de la existencia real de esos sujetos, que en esta mise en scene apelan al compromiso moral de aquellos que asisten como espectadores, con un padecimiento que pareciera estar mediado por la distancia temporal pero que se actualiza con cada manifestación pública: "El conjunto de imágenes incesantes (la televisión, el video continuo, las películas) es nuestro entorno, pero a la hora de recordar la fotografía cala más hondo. La memoria congela los cuadros; la unidad fundamental es la imagen individual". (Sontag, 2003, p. 31).

El uso de la fotografía para el reclamo por el destino de los desaparecidos se relaciona con una idea de "verosimilitud" que se asocia a la misma. Como ya dijimos en este trabajo las fotos funcionarían como "prueba" de la existencia del sujeto, al poner en la escena pública sus rostros. En relación con lo antes planteado es que citamos a Marta Penhos cuando indica que: "El impacto de la imagen fotográfica se debió a su fuerte carga persuasiva, a su pretendida objetividad. Cada foto se convirtió en un hecho plasmado, en un dato congelado". (Penhos, 2005, p. 51).

Esta idea de "verosimilitud" está ligada al uso de la fotografía como instrumento de denuncia de los hechos aberrantes. La creencia generalizada de que la fotografía "copia" o "reproduce" una realidad dada, le otorga un estatuto de verdad casi incuestionable a su registro, se constituye en un documento, en una prueba "irrefutable". Cuando la fotografía entra en la escena cualquier otra forma de memoria comienza a desvanecerse (Baer, 2006, p. 154). Como bien señala el autor antes citado, la imagen tiene una intensidad y un efecto de realidad mucho mayor que cualquier otra manifestación que tenga como objetivo la construcción de las memorias sociales.

Por otro lado, la fotografía, en algún sentido, significa una irrupción en el tiempo al hacer presente lo 
ausente. En relación a esto Roland Barthes (2006) considera que la imagen fotográfica sólo adquiere su valor pleno con la desaparición del referente, con la muerte del sujeto fotografiado. Al conservar eternamente su presencia fugaz, la esencia de la fotografía devela la obstinación del referente de estar siempre ahí (1980, p. 22).

Este corte temporal, implica a su vez un anclaje al renovar la vigencia de "aquello que ya no esta":

es una relación fatal con el referente, en nuestro caso el retratado, que está allí siempre presente y que Barthes llama spectrum para aludir a "ese algo terrible que hay en toda fotografía: el retorno de lo muerto"... el spectrum necesariamente ha existido, se instala la esencia de la fotografía, esto ha sido" (2005, p. 52).

Este subterfugio supone un doble movimiento narrativo, por un lado, el registro constante de la ausencia de sus protagonistas, a la vez que re-instalan la permanencia de los desaparecidos en la escena pública, como sujetos políticos, renovando constantemente su vigencia en cuanto tales. Así es que devienen "iconos" de una determinada lucha política de los setenta, que actualiza los reclamos de los organismos de Derechos Humanos.

Esta forma narrativa de exhibir las fotos-carnet condensa los mecanismos de construcción de los sujetos, que priorizan la persistencia del rostro en la memoria colectiva por encima de las escenas de la militancia. De este modo, “... se concentra en ese rostro que cuenta toda una historia, personal, pero también genérica”. (Penhos, 2006, p. 51)

Más allá de este doble juego fondo-figura mencionado anteriormente, representado por el uso de las siluetas y las fotografías en las manifestaciones públicas, en la foto-carnet también encontramos que se produce un desdoblamiento, donde el desaparecido deja de ser un anónimo para adquirir un nombre, una adscripción familiar, una historia personal, a la vez que una pertenencia que lo vincula a un grupo etario y social.

La utilización de la imagen del rostro de los desaparecidos en la escena pública cumple, desde nuestra perspectiva las funciones mencionadas ut supra. Ahora bien estas fotografías catalogadas como fotocarnet adquieren el estatuto de registro, cuya función en el sistema estatal es la de estandarizar la representación de aquellos que se consideran ciudadanos.

Tal como lo señala Susan Sontag: "Las fotografías fueron puestas al servicio de importantes instituciones de control, sobre todo la familia y la policía, como objetos simbólicos e informativos." (2006, p. 40).

Es en este sentido que, a través de prescripciones precisas como la preeminencia de la cara sobre un fondo neutro, procurando que la proporción de las imágenes guarden entre sí las mismas proporciones al tamaño real de los individuos fotografiados (Penhos, 2005), se tiende catalogar a los sujetos a partir de sus caras y se los inscribe en un sistema de normas, como pertenecientes a un Estado Nación, a una etnia, a un sexo; en definitiva como portadores de identidades distintivas y por lo tanto de derechos. Como bien señala Norbert Elias: "más que cualquier otra parte del cuerpo (la cara) es la vitrina de la persona." (1994, p. 160).

En el caso abordado, sostenemos que el uso de la foto-carnet subvierte el principio de la metodología de la desaparición forzada de las personas, al reinstalar a la víctima en el lugar legal del que fue excluido. Con la exhibición en las movilizaciones públicas de la foto-carnet se rescata al desaparecido de ese lugar al margen de la ley para reinstalarlo como ciudadano portador de derechos. En una segunda instancia la foto-carnet deviene instrumento de denuncia ante ese Estado que no cumplió con el contrato social (Reati, 2007). 
Entendemos que la foto-carnet funcionaría, en este contexto, como bisagra que marca la tensión entre la presencia y la ausencia, entre la nominación y la corporización, en la representación de la vida y de la muerte de aquellos por los que se reclama. La inauguración del uso de la foto-carnet en la escena pública viene de la mano de las Madres de Plaza de Mayo, quienes en un momento determinado abandonan la mera nominación para comenzar a portar las fotos colgadas de sus cuellos o prendidas en sus ropas.

La imagen del desaparecido en el cuerpo es una forma miniminal de exhibición pública que denota la fuerza del vínculo familiar primordial. Por contraste con el uso colectivo de las fotos de una marcha o una movilización, ésta es una práctica "individualizante" que expresa con nitidez el proceso general de transformación de una relación privada hacia un espacio público. (da Silva Catela, 2001, p. 137).

En este sentido, la paradoja de la utilización de la foto-carnet radica en su función: lo que en un momento sirvió de instrumento de control e identificación de futuras víctimas del terrorismo de Estado, ahora inaugura un nuevo espacio -en un nuevo contexto- en el ámbito público como instrumento de denuncia y soporte de la memoria.

Su utilización el 24 de marzo, en el ámbito de la Plaza de Mayo, da cuenta de las estrategias para mantener vigente el recuerdo de aquellos que están desaparecidos. Actualiza la performance que se renueva año a año ante nuevos públicos, cuyo objetivo es mantener viva la memoria ante la amenaza del olvido y reafirmar la demanda de justicia.

Desde nuestra perspectiva, la utilización de las fotografías como soportes de las memorias en las manifestaciones públicas, contribuyen a la construcción de distintos mecanismos de legitimación de los discursos sobre el proceso evocado y sus protagonistas.

\section{Palabras finales}

A modo de cierre, se intentará dar cuenta de algunos puntos que se consideran como los centrales en el tópico abordado. No constituyen conclusiones acabadas, dado que en el presente trabajo el tema no fue analizado en la multiplicidad de sus dimensiones. Por el contrario, pretenden ser el inicio de nuevas indagaciones sobre la problemática.

En primera instancia vale señalar que en el proceso de construcción de la identidad de los desaparecidos, el uso de la foto-carnet se constituye en uno de los soportes de la memoria. Adquiere una fuerza que le viene dada del poder de la imagen, por su preponderancia sobre los otros recursos, como figura icónica de la memoria en los actos conmemorativos del 24 de marzo en Plaza de Mayo. Como ya señalamos en este trabajo, cuando la fotografía entra en la escena, su fuerza es tal, que cualquier otra forma de memoria comienza a diluirse.

Esto tiene que ver, entre otras cosas, con el impacto de visibilidad que los sujetos fotografiados adquieren en el espacio público, con el proceso de identificación entre el que mira y el rostro plasmado en la foto y el efecto de verosimilitud que hace que la fotografía funcione como prueba de la existencia de ese sujeto y como objeto de denuncia.

En este proceso el uso de las fotos-carnets actualiza la demanda por la restitución del desaparecido. Demanda que surge del ámbito privado y se instala en el público. La exigencia que actualiza la fotocarnet explicita la restitución de este sujeto en su condición de ciudadano dentro de la ley. 
En este proceso se produce una reapropiación de la foto como instrumento que otrora fuera utilizado por las fuerzas armadas para identificar, fichar e individualizar a las víctimas de la represión, devenida ahora en herramienta de denuncia y de demanda por su restitución del sujeto dentro de la ley. La foto carnet es utilizada como soporte de la memoria, principalmente por las Madres de Plaza de Mayo y Familiares de desaparecidos quienes, desde nuestra perspectiva, ante la amenaza siempre latente del olvido reafirman la presencia del desaparecido en la escena pública a través de su imagen, su rostro siempre joven congelado en el tiempo. Esta amenaza tiene como contracara la creencia en la justicia, en la reinserción del desaparecido desde la clandestinidad del aparato estatal que lo hizo víctima hacia el lugar de ciudadano poseedor de derechos.

Al salir de la clandestinidad, al ser restablecido como ciudadanos, de lo que se trata es de la restitución de un nombre, de una historia, la de cada uno de los desaparecidos, para que dejen de ser un numero (referencia al colectivo de 30.000 desaparecidos), un NN. La ley con sus instrumentos serían los mecanismos a través del cual lograrlo.

\section{Notas}

1. El denominado "Proceso de Reorganización Nacional", se inicia con el golpe de Estado del 24 de marzo de 1976 y culmina en 1983.

2 El término performance hace referencia a un "repertorio reiterado de conductas repetidas" (Taylor) que como el trauma regresa una y otra vez, y se manifiesta corporalmente mucho después del evento original. Es una experiencia que siempre es presente y funciona como transmisor de la memoria al mismo tiempo que como su re-escenificación (Taylor, citada en Schindel, 2008).

\section{Referencias Bibliográficas}

Baer, A. (2006). Holocausto. Recuerdo y representación. Madrid: Losada.

Barthes, R. ( $3^{\mathrm{a}}$ ed.) (2006). La cámara lúcida. Nota sobre la fotografía. Buenos Aires: Paidós.

Bonaparte, L. (2006, otoño). Las Fotos. Ojos Crueles, Buenos Aires, 3. 17-22.

Castellani, D. (2003). La impunidad de los discursos. Buenos Aires: Nueva Generación.

Da Silvia Catela, L. (1997, setembro-decembro). Las memorias del horror: estilos e narrativas para comunicar el sufrimiento y el dolor por los desaparecidos en Argentina. Comunicacao \& Politica, 6, (3), nova serie.

Da Silvia Catela, L. (2001). No habrá flores en la tumba del pasado. La Plata: Ediciones Al Margen.

De Ipola, E. (1997). Las cosas del creer. Creencia, lazo social y comunidad política. Buenos Aires: Espasa Calpe Argentina/ Ariel. Elias, N. (1994). El proceso de la civilización. Investigaciones sociogenéticas y psicogenéticas. México: Fondo de Cultura Económica. Citado en Da Silvia Catela, L. (1997, setembro-decembro). Las memorias del horror: estilos e narrativas para comunicar el sufrimiento y el dolor por los desaparecidos en Argentina. Comunicacao \& Politica, 6,(3), nova serie. González Bombal, I. (1987). Derechos Humanos: La fuerza del acontecimiento. En AA.VV. El discurso político. Lenguajes y acontecimientos. Buenos Aires: Hachette.

Jelin, E. (Ed.) (2002). Las conmemoraciones: Las disputas en las fechas “in-felices”. Madrid: Siglo XXI.

Kossoy, B. (2001). Fotografía e Historia. Buenos Aires: Ed. La Marca.

Middleton, D. y Edwards, D. (Ed.) (1992). Memoria Compartida. La naturaleza social del recuerdo y del olvido. Buenos Aires: Paidós.

Penhos, Marta (2005). Frente y perfil. Una indagación acerca de la fotografía en las prácticas antropológicas y criminológicas en Argentina a fines del siglo XIX y principios del XX. En AAVV. Arte y Antropología en Argentina. Buenos Aires: 
Fundación Espigas.

Reati, F. (2007). El monumento de papel: la construcción de una memoria colectiva en los recordatorios de los desaparecidos. En Lorenzano, S. y Buchenhorst, R. (Ed.). Políticas de la memoria. Tensiones en la palabra y en la imagen. Buenos Aires: Gorla.

Sigal, S. (2006). La Plaza de Mayo: una crónica. Buenos Aires: Siglo XXI Editores.

(1999). Las Plazas de Mayo. En Altamirano, C. (Comp.). La Argentina en el siglo XX. Buenos Aires: Ariel.

Sontag, S. (2006). Sobre la fotografía. Buenos Aires: Alfaguara.

(2003). Ante el dolor de los demás. Buenos Aires: Alfaguara.

Schindel, E. (2008). Siluetas, rostros, escarches. Memoria y performance del movimiento de derechos humanos. En Longoni, A. y Brozzone, G. (Ed.). El siluetaza. Buenos Aires: Adriana Hidalgo editora.

Taylor, D. El espectáculo de la memoria: trauma, performance y política. En El despertador. Revista digital, www.eldesper tador.info/despierta/textdesper/memoperform. htm, citado en Schindel, E. (2008). Siluetas, rostros, escarches. Memoria $y$ performance del movimiento de derechos humanos. En Longoni, A. y Brozzone, G. (Comps.). El siluetaza. Buenos Aires: Adriana Hidalgo editora.

Summary: This work aims to approach to the use of photography as support of memory in the public demand of human rights. This particular case is focused on the victims of the last military dictatorship in Argentina . More specifically, in the use of the photo-card as a visual instrument in the public reclamation about destiny of missing people entitled by Human Rights organizations. These photo-cards were used as representation images of the disappeared during the commemoration acts of the 24 of March in Plaza de Mayo. These practices cross the public space and the private one, arising from the private to the public. The exigency that updates the explicit photo-card the restitution of this subject as its citizen within the law, by outside the clandestinity. And it tries to reinstate the image of these subjects in the public space.

Keywords: absence - commemoration - identity - law - memory - photography - subject.

Resumo: Este trabalho tem o objetivo de abordar o uso da fotografia como suporte da memoria na demanda pública pelos direitos humanos. Neste caso particular sobre a representação das vítimas do sistema represivo e como mecanismo de reclamo pela justiça ante a repressão ilegal levada adiante pelo terrorismo de Estado durante a última ditadura militar na Argentina. Mais especificamente, o uso da foto carteira no reclamo público pelo destino dos desaparecidos na Argentina. Fincaremos pé no uso que as diferentes organizações de direitos humanos fazem das fotos carteiras como modo de representação dos desaparecidos durante os atos de comemoração do 24 de março na praça de Maio.

Sustentamos que o uso das fotos carteiras atualiza a demanda pela restituição do desaparecido. Estas práticas atravessam tanto o espaço público como o privado, surgindo desde o privado para o público. A exigência que atualiza a foto carteira explicita a restituição deste sujeito em sua condição de cidadao dentro da lei, por fora da clandestinidade. E tenta reinstalar a imagem destes sujeitos no espaço público.

Palavras chave: ausencia - conmemoração - fotografia - identidade - lei - memoria - sujeito. 